\title{
Nephrolithiasis in ankylosing spondylitis and its relationship with disease assessment scales
}

\author{
D Aylin Rezvani, ${ }^{1}$ (1) Ilknur Aktas, ${ }^{2}$ (1) Nurettin Tastekin, ${ }^{3}$ (1) Reyhan Celiker, ${ }^{4}$ (D) Selda Sarikaya, ${ }^{5}$ \\ Did Erbil Dursun, ${ }^{6}$ (1) Senay Ozdolap, ${ }^{5}$ (1) Nigar Dursun, ${ }^{6}$ (1) Coskun Zateri, 7 (i) Lale Altan, ${ }^{8}$ \\ (D) Murat Birtane, ${ }^{3}$ (D) Kenan Akgun, ${ }^{9}$ (D) Necdet Sut ${ }^{10}$ \\ ${ }^{1}$ Department of Physical Medicine and Rehabilitation, Bezmialem Vakif University, Istanbul, Turkey \\ ${ }^{2}$ Department of Physical Medicine and Rehabilitation, Health Science University Fatih Sultan Mehmet Training and Research Hospital, \\ Istanbul, Turkey \\ ${ }^{3}$ Department of Physical Medicine and Rehabilitation, Trakya University Faculty of Medicine, Edirne, Turkey \\ ${ }^{4}$ Department of Physical Medicine and Rehabilitation, Acibadem University Faculty of Medicine, Istanbul, Turkey \\ ${ }^{5}$ Department of Physical Medicine and Rehabilitation, Bulent Ecevit University Faculty of Medicine, Zonguldak, Turkey \\ ${ }^{6}$ Department of Physical Medicine and Rehabilitation, Kocaeli University Faculty of Medicine, Izmit, Turkey \\ ${ }^{7}$ Department of Physical Medicine and Rehabilitation, Canakkale Onsekiz Mart University Faculty of Medicine, Canakkale, Turkey \\ ${ }^{8}$ Department of Physical Medicine and Rehabilitation, Uludag University Faculty of Medicine, Bursa, Turkey \\ ${ }^{9}$ Department of Physical Medicine and Rehabilitation, Istanbul University Cerrahpasa Faculty of Medicine, Istanbul, Turkey \\ ${ }^{10}$ Department of Biostatistics, Trakya University Faculty of Medicine, Edirne, Turkey
}

\begin{abstract}
OBJECTIVE: The aim of this study was to investigate the frequency of renal calculi in patients with ankylosing spondylitis (AS) and to determine its relationship with disease assessment variables.

METHODS: The study was designed retrospectively, and it included a cohort of 320 patients with AS diagnosed using the Modified New York Criteria. A total of 119 patients who underwent renal ultrasonography (USG), in who the erythrocyte sedimentation rate, C-reactive protein, blood calcium, phosphorus, Vitamin D, parathormone, and urinary calcium excretion were measured, and who also had lateral cervical and lumbar radiography in the same time period were extracted from the cohort. All patients' demographic characteristics and the results of blood and urine tests were recorded. The Ankylosing Spondylitis Disease Activity Index (BASDAI), Ankylosing Spondylitis Functional Index (BASFI), Ankylosing Spondylitis Mobility Index (BASMI), and Modified Stoke Ankylosing Spondylitis Spinal Score (mSASSS) were evaluated in all patients.

RESULTS: Thirteen of the 119 patients had renal calculi confirmed by USG data. The frequency of nephrolithiasis detected by USG was $10.9 \%$ in patients with AS. The disease lasted significantly longer in patients with renal calculi ([nephrolithiasis $(+): 18.39 \pm 8.72$ years; nephrolithiasis $(-): 12.02 \pm 8.43$ years, $\mathrm{p}=0.01]$ ). The BASMI total score was significantly higher in the group of patients with renal calculi. There was not any significant difference in terms of blood samples, HLA-B27, BASDAI, BASFI, and mSASSS between groups.

CONCLUSION: The frequency of renal stones is increased in patients with AS compared to healthy population. Especially patients who had AS for a long time and higher BASMI values are more susceptible to renal calculi. It is important to point out that the results of this type of studies would be more reliable if the study is conducted on large patient groups and population-based prevalence.
\end{abstract}

Keywords: Ankylosing spondylitis; BASDAI; BASFI; BASMI; mSASSS; nephroilitasiz; urolithiasis.

Cite this article as: Rezvani A. Aktas I, Tastekin N, Celiker R, Sarikaya S, Dursun E, et al. Nephrolithiasis in ankylosing spondylitis and its relationship with disease assessment scales. North Clin Istanb 2019;6(3):254-259.

Received: March 26, 2018 Accepted: May 12, 2018 Online: August 08, 2018

Correspondence: Dr. Aylin REZVANI. Bezmialem Vakif Universitesi Tip Fakultesi, Fiziksel Tip ve Rehabilitasyon Anabilim Dali, Istanbul, Turkey.

Tel: +902124531700 e-mail: rezvani.aylin@gmail.com

(c) Copyright 2019 by Istanbul Provincial Directorate of Health - Available online at www.northclinist.com 
A nkylosing spondylitis (AS) is a chronic inflammatory disease with the predilection for the spine and sacroiliac joints, thus causing back pain and post-inactivity stiffness [1]. In addition, AS can manifest itself as peripheral arthritis and enthesitis, and it can also have extra-articular involvement such as the eye, lung, kidney, and heart [1]. The prevalence of AS is generally believed to be $0.1 \%-1.4 \%$, and the gender disparity is reported as the male-to-female ratio of around $2: 1[2]$.

IgA nephropathy, secondary amyloidosis, and analgesic nephropathy represent the most common renal involvement seen in AS [3]. However, the incidence of renal calculi has been shown to be higher in these patients than in normal populations [4]. The prevalence of urolithiasis ranges from $2 \%$ to $20 \%$ throughout the world, based on different population characteristics [5]. With a prevalence of $11.1 \%$, urinary calculi disease is considered endemic in Turkey, and it shows a specific geographical distribution, where the south-eastern Anatolian and Aegean regions have the highest prevalence [6].

Several studies showing an increased incidence of renal calculi in patients with AS have been published [7-13]. Jacobsen et al. found the risk of nephrolithiasis in patients with AS to be more than twofold compared to the general population. The authors described nephrolithiasis as an extra-articular manifestation in AS and factors such as the male gender, history of inflammatory bowel disease, and previous history of kidney stones were significant and clinical important predictors of nephrolithiasis in patients with AS [12]. Furthermore, a recently published study from Taiwan with a large patient number assessed the risk of nephrolithiasis among patients with AS compared to matched general population. The percentages of newly diagnosed nephrolithiasis were $5.76 \%$ in AS and $4.58 \%$ in the non-AS patients. The results showed that patients with AS were more likely to be associated with nephrolithiasis than non-AS patients [14].

Although its etiology is unknown, the formation of calculi requires a complex integration of numerous factors, such as high blood calcium and phosphate saturation, high levels of urinary calcium, the formation, retention, and accumulation of crystals, urinary $\mathrm{pH}$, and abnormalities in crystallization inhibitors [15]. In addition to an increased level of cytokines, bone resorption, and increased bone turnover, a prolonged use of anti-inflammatory drugs and accompanied intestinal problems also play a role in calculi formation in AS [16].
In the light of the information provided, the aim of this study was to investigate the frequency of detected renal calculi by ultrasonography (USG) and its relationship with disease assessment scales in our patients with AS.

\section{MATERIALS AND METHODS}

The study was designed retrospectively. A total of 320 patients with AS being followed by the "Activity Platform" were included in the study. The Activity Platform is comprised of 11 physiatrists from nine different centers in Turkey, showing a special interest in spondyloarthritis and rheumatoid arthritis, who have received a standardized training that included examination, an assessment of the questionnaire forms, and radiological grading performance of patients with AS. A total of 119 patients who had renal USG, erythrocyte sedimentation rate, Creactive protein, blood level of calcium, phosphorus, $\mathrm{Vi}$ tamin D, parathormone, and urinary calcium levels, and also lateral cervical and lumbar conventional radiography in the same time period were extracted from the cohort.

All of the AS cases were diagnosed according to the Modified New York Criteria [17]. The sociodemographic characteristics (age, gender, and disease duration), clinical features, and comorbidities were recorded. Patients who had a history of hypertension, diabetes, and cardiovascular disease were excluded. Patients were identified as "renal calculi positive" with calculi-compatible images and "renal calculi negative" if they were calculi incompatible. A written informed consent was obtained from each patient.

The patients were assessed using the Assessment of SpondyloArthritis International Society recommendations for core outcome domains in the AS assessment [18]. Turkish versions of Bath AS Disease Activity Index (BASDAI) [19], Turkish version of Bath AS Functional Index (BASFI) [20], and Bath AS Metrology Index (BASMI) [21] were evaluated for disease activity, functional status, and mobility, respectively. The BASMI subscale was calculated using the chest expansion, cervical rotation, lumbar flexion, lumbar lateral flexion, and intermalleolar distance evaluations. A Modified Stoke Ankylosing Spondylitis Spinal Score (mSASSS) [22] was used for the radiological assessment of structural damage. For this reason, lateral views of the lumbar and cervical spine of 119 patients also having renal ultrasonographic evaluation in the same time period were scored by the same researcher (R.Ç.) experienced in grading the mSASSS 
TABLE 1. Demographic characteristics of as patients with and without nephrolithiasis

\begin{tabular}{lccc} 
Characteristics & Nephrolithiasis (-) & Nephrolithiasis (+) & $\mathrm{p}$ \\
\hline Age (years) & $40.42 \pm 10.59$ & $45.69 \pm 10.10$ & 0.91 \\
Male gender & $\% 61$ & $\% 84.6$ & 0.13 \\
Disease duration (years) & $12.02 \pm 8.43$ & $18.39 \pm 8.72$ & $\mathbf{0 . 0 1} *$ \\
HLA B27 (+) & $93 / 106$ & $13 / 13$ & 0.33 \\
\hline
\end{tabular}

$* \mathrm{p}<0.05$.

TABLE 2. Laboratory results of patients in the same time period of ultrasonographic evaluation

\begin{tabular}{lccc} 
Characteristics & Nephrolithiasis $(-)$ & Nephrolithiasis $(+)$ & $p$ \\
\hline Calcium $(\mathrm{mg} / \mathrm{dl})$ & $10.11 \pm 8.24$ & $9.42 \pm 0.36$ & 0.45 \\
Phosphorus $(\mathrm{mg} / \mathrm{dl})$ & $3.30 \pm 0.58$ & $3.19 \pm 0.53$ & 0.59 \\
Vitamin D $(\mathrm{ng} / \mathrm{ml})$ & $29.36 \pm 33.92$ & $23.87 \pm 10.06$ & 0.89 \\
Parathormon $(\mathrm{pg} / \mathrm{ml})$ & $55.79 \pm 31.01$ & $57.03 \pm 41.59$ & 0.55 \\
Urine calcium $(24 \mathrm{~h})$ & $145.04 \pm 84.97$ & $238.91 \pm 403.70$ & 0.76
\end{tabular}

[22]. The frequency of nephrolithiasis in our patients was assessed by comparing it to Turkish population nephrolithiasis data.

\section{Statistics}

We used a chi-squared and/or Fisher's exact test to compare categorical variables such as nephrolithiasis between the patients with AS and normal population. An independent two-samples t-test was used to compare continuous variables such as mSASSS, BASFI, BASMI, an BASDAI scores between the patients with AS with and without nephrolithiasis. In each case, a p-value $<0.05$ was considered to be statistically significant. A data analysis was performed using the SPSS version 18.

\section{RESULTS}

Thirteen of 119 patients included in the study had renal calculi confirmed by USG data. The prevalence of nephrolithiasis detected by USG was $10.9 \%$ in our patients with AS. One hundred and six patients had no history of renal calculi and no compatible renal calculi in USG. There was no difference in age, gender, and the HLA-B27 positivity between AS patients with and without renal calculi $(p>0.05)$. Disease duration was significantly higher in patients with renal calculi (nephrolithiasis $[+]: 18.39 \pm 8.72$ years, nephrolithiasis $[-]: 12.02 \pm 8.43$ years, $p=0.01)$. Demographic characteristics of the patients are presented in Table 1 .

There was no significant difference in the serum calcium, phosphorus, Vitamin D, parathormone, and urinary calcium excretion results obtained on the same date of USG evaluation in patients from both groups $(>0.05)$ (Table 2).

There was no significant difference in terms of BASFI between the two groups (Table 3). The BASMI total score was significantly higher in the group of renal calculi positive patients. Although no significant difference was observed between the two groups in terms of chest expansion, lateral spinal flexion, a modified Schober test, and intermalleolar distance in the BASMI subscale, the tragus-wall distance was significantly increased, and cervical rotation values were significantly decreased in patients with renal calculi.

The mSASS values were $39.08 \pm 22.72$ in patients with renal calculi and $32.09 \pm 16.76$ in the other group. There was no significant difference in terms of mSASS between the two groups $(p=0.244)$ (Table 4$)$. 
TABLE 3. The relationship between nephrolithiasis and BASMI subscale

\begin{tabular}{lcccccc} 
& $\begin{array}{c}\text { Chest } \\
\text { expantion }(\mathrm{cm})\end{array}$ & $\begin{array}{c}\text { Cervical } \\
\text { rotation (degree) }\end{array}$ & $\begin{array}{c}\text { Tragus to wall } \\
\text { distance }(\mathrm{cm})\end{array}$ & $\begin{array}{c}\text { Lateral spinal } \\
\text { flexion }(\mathrm{cm})\end{array}$ & $\begin{array}{c}\text { Modified schober } \\
\text { test }(\mathrm{cm})\end{array}$ & $\begin{array}{c}\text { Intermalleolar } \\
\text { distance }(\mathrm{cm})\end{array}$ \\
\hline Nephrolithiasis (-) & $3.79 \pm 1.71$ & $61.09 \pm 22.41$ & $16.23 \pm 5.58$ & $11.24 \pm 6.26$ & $4.13 \pm 2.06$ & $93.47 \pm 19.13$ \\
Nephrolithiasis (+) & $3.04 \pm 1.68$ & $42.04 \pm 27.30$ & $19.68 \pm 5.94$ & $7.83 \pm 5.05$ & $3.29 \pm 1.80$ & $90.88 \pm 25.12$ \\
p & 0.156 & $\mathbf{0 . 0 1 *}$ & $\mathbf{0 . 0 2 *}$ & 0.07 & 0.20 & 0.86 \\
\hline
\end{tabular}

BASMI: Ankylosing Spondylitis Mobility Index; ${ }^{*} \mathrm{p}<0.05$.

TABLE 4. The relation of nephrolithiasis with BASMI, BASFI, BASDAI, and mSASS

\begin{tabular}{lcccc} 
& BASMI & BASFI & BASDAI & mSASS \\
\hline Nephrolithiasis (-) & $3.50 \pm 2.45$ & $3.11 \pm 2.30$ & $3.69 \pm 2.34$ & $32.08 \pm 16.76$ \\
Nephrolithiasis $(+)$ & $5.17 \pm 2.44$ & $3.28 \pm 2.77$ & $3.17 \pm 2.75$ & $39.08 \pm 22.72$ \\
$\mathrm{p}$ & $0.02^{*}$ & 0.93 & 0.40 & 0.24 \\
\hline
\end{tabular}

BASMI: Ankylosing Spondylitis Mobility Index; BASFI: Ankylosing Spondylitis Functional Index; BASDAI: Ankylosing spondylitis disease activity Index; mSASS: Modified Stoke Ankylosing Spondylitis Spinal Score; ${ }^{*} p<0.05$.

\section{DISCUSSION}

Considering the results of our study in general, the frequency of renal calculi was found to be $10.9 \%$ in our patients with AS. The presence of renal calculi was correlated with mobility indices (BASMI) and were more common in AS patients with a longer disease duration.

An extra-articular involvement is common in inflammatory diseases. Although renal involvement has been shown in many studies on AS, the number of studies investigating the coexistence of renal calculi in AS is very limited [7-13].

The frequency of renal calculi in our patients with AS was $10.9 \%$. Our results were compatible with other studies. A significantly higher prevalence of urolithiasis in patients with AS (11.7\%) versus normal population (5.7\%) was reported by Fallahi et al. [13]. Korkmaz et al. reported that renal calculi were more common in patients with AS (20\%) than with Behçet's disease (5.5\%) and healthy controls (3.3\%) [4]. They found renal calculi to be more common in their patients who had AS for a longer time. Canales et al. reported the increased frequency of renal stones in patients with spondyloarthropathies (29\%) versus rheumatoid arthritis (12\%) [23].
On the contrary, Incel et al. reported no difference in the frequency of renal calculi in patients with AS and normal population. It may be related with the low number of patients in their study [24].

Many factors such as spinal immobilization, the presence of inflammatory cytokines, new bone formation, and a prolonged use of nonsteroidal anti-inflammatory agents has been associated with alterations in calcium metabolism [15]. On the other hand, there are many factors that contribute to the process of calculi formation in as duration of the disease, the effect of conditions such as the immobility and treatment process, urinary tract infection, changes in urinary $\mathrm{pH}$, urostasis, metabolic diseases, congenital abnormalities, heredity, dietary, climate, and occupation [25].

Although of unknown etiology, the formation of calculi requires a complex integration of numerous factors. Resorlu et al, reported that $80 \%-90 \%$ of the renal calculi in patients with AS were calcium-based calculi supporting the possibility of problem primarily due to calcium metabolism [10].

It is stated that osteopenia associated with calcium metabolism impairment in AS increases the frequency of calcium-induced renal calculi. Here with the pathologi- 
cal process of resorption, the predominance of formation phase in the bone cycle could also affect the formation of renal calculi [24].

In a recent prospective study, Gonullu et al. found a significantly higher level of blood calcium at the baseline in AS patients with compared to AS patients without renal calculi [11]. Although this study did not reach statistical significance, the authors also found high urinary calcium levels compared to patients who did not have calculi. They concluded that a subgroup of AS patients tend to have high blood and urinary calcium and that these biochemical abnormalities and other factors might be responsible for the development of urolithiasis [11]. Our study was not in line with their trial as we could not find any significant difference in the blood level of calcium, phosphorus, Vitamin D, parathormone, and urinary calcium excretion.

Lui et al. found a functional disability (BASFI) and disease activity (BASDAI) to be greater in AS patients with renal calculi, but no significant differences were detected in the mobility index (BASMI) [8]. They found a significant association with Crohn's disease in AS patients with urolithiasis [8]. Similarly, Fallahi et al. found a significantly higher BASFI, BASMI, and BASDAI in their AS patients with urolithiasis [13]. There was not any significant difference in terms of BASFI and BASDAI in our study, but on contrary, BASMI showed to be significantly worse in patients with AS who had renal calculi. It has been stated that renal calculi do not occur in AS patients with long disease duration. Our results confirm this piece of information, as in our study, the frequency of renal calculi was found to be significantly higher in both AS patients with long disease duration and with low BASMI values, which do occur in established patients.

The absence of difference in the intermalleolar distance may be related to the fact that osteoproliferation is more intense in the spine than in the hips. Although there are apparent differences, the statistical insignifcance in the chest expansion and the Schober test may be related to the late involvement of costochondral and costovertebral joints.

In contrast to general expectation in believing that renal calculi accompanies AS cases with more severe radiographic damages and a presumably poor prognosis, Lui et al. found no significant difference in terms of mSASSS in their AS patients with a history of renal calculi [8]. Although there was a higher radiological score, Cansu et al. also did not report any significant differences in AS patients with urolithiasis [9].

Our study was compatible with these two studies. Interestingly, at the molecular level, an increased amount of bone-related proteins such as osteonectin, osteoprotegerin, bone sialoprotein, and transcription factors evolving in bone ossification have been found in the epithelial kidney cell, which can differentiate into an osteoblastic phenotype in the pathogenesis of renal calculi formation [26]. Although common features are involved in the pathogenesis of bone ossification and renal stone formation, the inconsistency of results suggests the other unknown factors and pathways should be researched in the future.

There were some limitations to our study. One of them was its retrospective design. Nevertheless, despite the retrospective study, we found an increased frequency of renal calculi in patients with AS parallel with the literature, showing the presence of urolithiasis in these patients, which should be taken into consideration. The second one was the evaluation of mSASSS, which could have been more valid if it had been done by two of our investigators instead of one. Finally, the third limitation were the patients' treatment data, which were not included in our study.

\section{Conclusion}

Evaluating all these data, we can easily conclude that the frequency of renal calculi is increased in patients with AS. Especially, patients who had AS for a long time and higher BASMI scores are more susceptible to renal calculi, and the evaluation of nephrolithiasis should not be forgotten in such patients. It is important to point out that the results of this type of studies are more reliable if the study includes large patient groups and populationbased prevalence.

Conflict of Interest: The authors declare no conflict of interest.

Financial Disclosure: The authors declared that this study has received no financial support.

Authorship Contributions: Concept - AR, IA, NT, RC, SS, ED, SO, ND, CZ, LA, MB, KA; Supervision - IA, RC, ED, ND, LA, MB, KA; Materials - AR, IA, NT, RC, SS, ED, SO, ND, CZ, LA, MB, KA; Data collection and/or processing - AR, IA, NT, RC, SS, ED, SO, ND, CZ, $\mathrm{LA}, \mathrm{MB}, \mathrm{KA}$; Analysis and/or interpretation - AR, NS; Writing - AR; Critical review - IA, NT, RC, SS, ED, SO, ND, CZ, LA, MB, KA.

\section{REFERENCES}

1. Gran JT, Husby G. The epidemiology of ankylosing spondylitis. Semin Arthritis Rheum 1993;22:319-34. [CrossRef] 
2. Dean LE, Jones GT, MacDonald AG, Downham C, Sturrock RD, Macfarlane GJ. Global prevalence of ankylosing spondylitis. Rheumatology (Oxford) 2014;53:650-7. [CrossRef]

3. Vilar MJ, Cury SE, Ferraz MB, Sesso R, Atra E. Renal abnormalities in ankylosing spondylitis. Scand J Rheumatol 1997;26:19-23. [CrossRef]

4. Korkmaz C, Ozcan A, Akçar N. Increased frequency of ultrasonographic findings suggestive of renal stones in patients with ankylosing spondylitis. Clin Exp Rheumatol 2005;23:389-92.

5. Otunctemur A, Ozbek E, Cakir SS, Dursun M, Polat EC, Ozcan L, et al. Urolithiasis is associated with low serum testosterone levels in men. Arch Ital Urol Androl 2015;87:83-6. [CrossRef]

6. Muslumanoglu AY, Binbay M, Yuruk E, Akman T, Tepeler A, Esen T, et al. Updated epidemiologic study of urolithiasis in Turkey. I: Changing characteristics of urolithiasis. Urol Res 2011;39:309-14. [CrossRef]

7. Singh G, Kumari N, Aggarwal A, Krishnani N, Misra R. Prevalence of subclinical amyloidosis in ankylosing spondylitis. J Rheumatol 2007;34:371-3.

8. Lui NL, Carty A, Haroon N, Shen H, Cook RJ, Inman RD. Clinical correlates of urolithiasis in ankylosing spondylitis. J Rheumatol 2011;38:1953-6. [CrossRef]

9. Cansu DU, Calışır C, Savaş Yavaş U, Kaşifoğlu T, Korkmaz C. Predictors of radiographic severity and functional disability in Turkish patients with ankylosing spondylitis. Clin Rheumatol 2011;30:557-62.

10. Resorlu M, Gokmen F, Resorlu H, Adam G, Aylanc N, Akbal A, et al. Prospective evaluation of the renal morphology and vascular resistance in patients with ankylosing spondylitis. Med Ultrason 2015;17:180-4.

11. Gönüllü E, Bilge NŞY, Cansu DU, Bekmez M, Musmul A, Akçar N, et al. Risk factors for urolithiasis in patients with ankylosing spondylitis: a prospectivecase-control study. Urolithiasis 2017;45:353-7. [CrossRef]

12. Jakobsen AK, Jacobsson LT, Patschan O, Askling J, Kristensen LE. Is nephrolithiasis an unrecognized extra-articular manifestation in ankylosing spondylitis? A prospective population-based Swedish national cohort study with matched general population comparator subjects. PLoS One 2014;9:e113602. [CrossRef]

13. Fallahi S, Jamshidi AR, Gharibdoost F, Mahmoud MI, Paragomi P, Nicknam $\mathrm{MH}$, et al. Urolithiasis in ankylosing spondylitis: Correlation with Bath ankylosing spondylitis disease activity index (BASDAI), Bath ankylosing spondylitis functional index (BASFI) and Bath ankylosing spondylitis metrology index (BASMI). Caspian J Intern Med
2012;3:508-13.

14. Shih MT, Tang SH, Cha TL, Wu ST, Chiang JH, Chen WC. The Risk of Nephrolithiasis Among Patients With Ankylosing Spondylitis: a Population-Based Cohort Study. Arch Rheumatol 2016;31:346-52.

15. Khan SR. Reactive oxygen species, inflammation and calcium oxalate nephrolithiasis. Transl Androl Urol 2014;3:256-76.

16. Toussirot E, Wendling D. Osteoporosis in ankylosing spondylitis. [Article in French]. Presse Med 1996;25:720-4.

17. van der Linden S, Valkenburg HA, Cats A. Evaluation of diagnostic criteria for ankylosing spondylitis. A proposal for modification of the New York criteria. Arthritis Rheum 1984;27:361-8. [CrossRef]

18. van der Heijde D, Calin A, Dougados M, Khan MA, van der Linden S, Bellamy N. Selection of instruments in the core set for DC-ART, SMARD, physical therapy, and clinical record keeping in ankylosing spondylitis. Progress report of the ASASWorking Group. Assessments in Ankylosing Spondylitis. J Rheumatol 1999;26:951-4.

19. Akkoc Y, Karatepe AG, Akar S, Kirazli Y, Akkoc N. A Turkish version of the Bath Ankylosing Spondylitis Disease Activity Index: reliability and validity. Rheumatol Int 2005;25:280-4. [CrossRef]

20. Karatepe AG, Akkoc Y, Akar S, Kirazli Y, Akkoc N. The Turkish versions of the Bath Ankylosing Spondylitis and Dougados Functional Indices: reliability and validity. Rheumatol Int 2005;25:612-8. [CrossRef]

21. Jenkinson TR, Mallorie PA, Whitelock HC, Kennedy LG, Garrett SL, Calin A. Defining spinal mobility in ankylosing spondylitis (AS). The Bath AS Metrology Index. J Rheumatol 1994;21:1694-8.

22. Creemers MC, Franssen MJ, van't Hof MA, Gribnau FW, van de Putte LB, van Riel PL. Assessment of outcome in ankylosing spondylitis: an extended radiographic scoring system. Ann Rheum Dis 2005;64:127-9.

23. Canales BK, Leonard SM, Singh JA, Orzano IM, Zimmermann B, Weiland D, et al. Spondyloarthropathy: an independent risk factor for kidney stones. J Endourol 2006;20:542-6. [CrossRef]

24. Incel NA, Gökoğlu F, Nacir B, Incel N. Bone and stone in ankylosing spondylitis: osteoporosis and urolithiasis. Clin Rheumatol 2006;25:667-70. [CrossRef]

25. Drach GW. Urinary lithiasis. In: Campbell's urology, vol II. Saunders, Philadelphia; 1986; p. 1094.

26. Gambaro G, Fabris A, Abaterusso C, Cosaro A, Ceol M, Mezzabotta F, et al. Pathogenesis of nephrolithiasis: recent insight from cell biology and renal pathology. Clin Cases Miner Bone Metab 2008;5:107-9. 